\title{
A REPRESENTAÇÃO SOCIAL DE ÁREAS VERDES EM CIDADES: O CASO BOSQUE RODRIGUES ALVES - JARDIM BOTÂNICO DA AMAZÔNIA
}

\author{
Homero Vilar CORREA ${ }^{1}$ \\ Universidade Federal do Pará \\ homero@ufpa.br
}

\begin{abstract}
Resumo: O presente estudo direcionou-se a abordar a representação social de áreas verdes, enfatizando o caso do Bosque Rodrigues Alves. Assim, tomando por base a pesquisa realizada ressaltam-se as representações sociais que os frequentadores do Bosque atribuem a este logradouro de grande relevância paisagística, ambiental, patrimonial e histórica para a cidade de Belém. No caso especifico desse estudo, o foco da pesquisa concentra-se no papel social exercido pelo Jardim Botânico, em especial o Bosque Rodrigues Alves, Jardim Botânico da Amazônia, e sua representação social para os moradores da cidade de Belém. No que se refere à pesquisa desenvolvida, ressalta-se que esta apresenta cunho descritivo e também explicativo, esclarecendo os fatores contributivos e interferidores, condicionantes da questão estudada.
\end{abstract}

Palavras-chave: Representação Social. Áreas Verdes. Bosque Rodrigues Alves.

Abstract: This study was directed toward addressing the social representation of green areas, emphasizing the case of the Bosque Rodrigues Alves. Thus, based on a survey we emphasize the social representations that the patrons of the Grove Street address to attach to this very important landscape, environmental, heritage and history to the town of Belem. In the specific case of this study, the focus of research focuses on the social role played by the Botanical Gardens, especially the Bosque Rodrigues Alves, Botanical Garden in the Amazon and its social representation to residents of the town of Bethlehem With regard to research developed, it is emphasized that it presents a descriptive and explanatory as well, clarifying the contributing factors and jammers, affecting the issue studied.

Keywords: Social Representation. Green Areas. Bosque Rodrigues Alves.

\footnotetext{
${ }^{1}$ Mestre em Ciências Ambientais pela Universidade Federal do Pará.
} 


\section{Introdução}

As cidades representam as mais profundas e radicais intervenções humanas sobre a superfície do planeta. Elas refletem os diferentes ambientes culturais e as variadas estruturas econômicas que envolveram a sua produção. Por isso, pode-se dizer que as cidades são frutos de contextos sociais e caracterizam-se também pelas relações de uso e apropriação dos espaços construídos, estabelecidas pelos usuários dos cenários urbanos. Dessa forma, a cidade configurase em uma fonte geradora de estímulos perceptivos para quem habita, entendendo por percepção basicamente a capacidade de gerar informação nova e diferenciada a partir dos elementos percebidos. $\mathrm{O}$ espaço pode ser compreendido a partir das informações que se têm sobre ele, o que gera uma relação de interdependência entre o espaço e a informação.

Tomando por referência a explanação acima, destaca-se, no cenário em foco, que o espaço urbano traduz a atividade laboral humana. Ele congrega o imaginário e as representações de gerações, que tomaram parte no processo de construção da fixação de homens e mulheres na terra. De um lado, as fantasias das gerações mais recentes convivem com as gerações antigas: a cidade preserva a memória do seu passado. De outro, outras fantasias são erguidas sobre as ruínas daquelas que permanecem submersas, num movimento contínuo de construção e reconstrução.

O espaço produzido, especialmente o urbano, reflete intencionalidades, ideias e representações. Também o espaço, designado como natureza, junto ao conhecimento advindo dele, historicamente, expressa as ações socioculturais. Assim, considerouse pertinente realizar um estudo sobre a representação social de áreas verdes em cidades, uma vez que a evolução das estruturas arquitetônicas da cidade, decorrente das ações sociopolíticoeconômicas, fez parecer que o verde foi cedendo o seu lugar para a construção de pedras sobre pedras, alterando as condições ambientais da vida urbana. Os riscos ambientais decorrentes das novas formas de

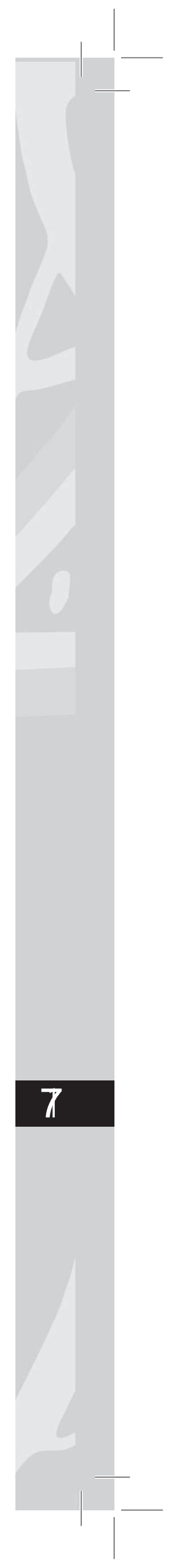




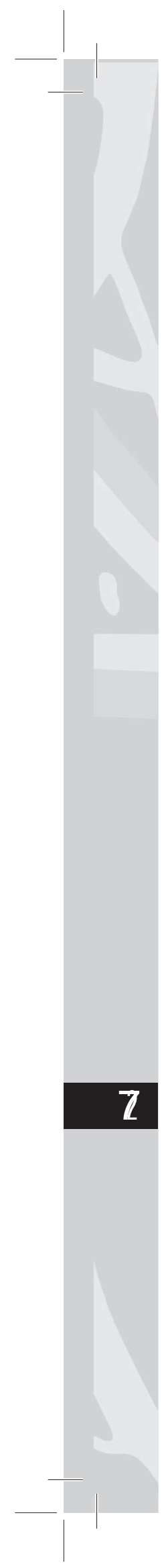

produção é presente na vida dos citadinos, assim como o surgimento de novos espaços de lazer, como os shopping centers, atrai um número significativo de moradores da cidade, na medida em que os apelos midiáticos enfatizam muito mais o consumo do que seus efeitos sobre a sociedade.

Neste estudo intitulado "As representações sociais de áreas verdes em cidades: o caso Bosque Rodrigues Alves", busca-se investigar as diversas representações sociais que os frequentadores do Bosque atribuem a este logradouro de grande relevância paisagística, ambiental, patrimonial e histórica para a cidade de Belém.

Ressalta-se que o problema formulado para a presente investigação, indaga: Quais são as representações sociais que os frequentadores do Bosque Rodrigues Alves - Jardim Botânico da Amazônia possuem sobre esta área verde?

Com relação aos objetivos do trabalho, destaca-se como objetivo geral: identificar as representações sociais dos frequentadores do Bosque sobre esta área verde; e como objetivos específicos: contextualizar o surgimento do Bosque Rodrigues Alves na cidade de Belém; identificar a importância do Bosque Rodrigues Alves para os seus frequentadores; caracterizar as imagens e sentidos partilhados e/ou consensuais sobre o Bosque Rodrigues Alves pelos seus frequentadores. No caso específico desse estudo, o foco da pesquisa concentra-se no papel social exercido pelo Jardim Botânico, em especial o Bosque Rodrigues Alves, Jardim Botânico da Amazônia, e sua representação social para os moradores da cidade de Belém.

No que se refere à pesquisa desenvolvida, ressalta-se que esta apresenta cunho descritivo e também explicativo, esclarecendo os fatores contributivos e interferidores, condicionantes da questão estudada. Quanto aos meios, a pesquisa bibliográfica foi desenvolvida com base em materiais coletados no decorrer do desenvolvimento do Projeto de Pesquisa e, ainda, em outras fontes disponíveis no acervo, principalmente livros e artigos científicos, sejam estes de leitura corrente ou de referência, que possibilitaram a obtenção de informações referentes ao tema em questão, considerando que a 
pesquisa aqui desenvolvida se propôs a diversas verificações e análises de disposições acerca de um mesmo problema.

\section{Revisão da literatura}

\subsection{A sustentabilidade nas cidades brasileiras e a realidade do Bosque Rodrigues Alves: "Jardim Botânico da Amazônia"}

Tomando por base as colocações de Ferreira (2004), é possível afirmar que o crescimento das cidades encontra-se interligado ao alto índice de migração, responsável pelo "inchaço" populacional e, consequentemente, pela deterioração da qualidade de vida. Para tanto, de modo a manter um equilíbrio entre índice populacional e qualidade de vida, torna-se necessário a realização de uma reorganização urbana, fato que já é uma preocupação em alguns locais que implementaram iniciativas de gerenciamento integrado das atividades urbanas com o intuito de melhorar a qualidade de vida da população e preservar o equilíbrio ambiental.

Desse modo, as cidades passaram a se defrontar com uma situação grave que exige intervenções ágeis em áreas que extrapolam as tradicionais políticas na área urbana. Trata-se de amplos projetos de infraestrutura, políticas sociais, programas de emprego e políticas ambientais, envolvendo inclusive estratégias locais de dinamização das atividades econômicas. Os municípios situam-se na linha de frente dos problemas, mas estão no último escalão da administração pública. Há um deslocamento generalizado dos problemas para a esfera local, enquanto as estruturas político-administrativas continuam centralizadas. Esse processo criou um tipo de impotência institucional que dificulta dramaticamente qualquer modernização da gestão local. Com o processo de urbanização, os problemas se deslocaram, mas não o sistema de decisão correspondente.

Neste processo, avaliando o espaço urbano de Belém, em sua formação, observa-se que ele apresentava, em sua composição, 


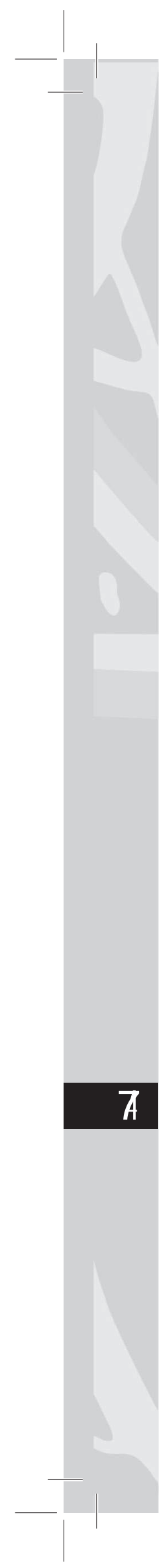

instituições de controle e reprodução social, como: praças ajardinadas, edifícios da administração pública, várias escolas, hospitais, asilos e cadeia. Junto a este conjunto, estavam as indústrias, as casas bancárias e as firmas seguradoras, com inúmeros serviços e atividades, fora as companhias de serviços urbanos, tais como: telégrafos, telefonia, linhas de bonde e estradas de ferro. E, em prol da melhoria do espaço urbano de Belém, seja em relação à estética ou ao saneamento básico, o governador elegeu, à época, uma comissão que apresentasse propostas otimizadoras para tais fins.

Assim, foram construídos pontilhões, abertas e reabertas as valas, concluídos passeios, iniciados calçamentos, reparados edifícios municipais e projetados outros. Os lagos foram ajardinados, os calçamentos de madeira foram substituídos por granitos. Foi ordenada a abertura de inúmeras ruas e travessas no bairro do Marco, e promovido o melhoramento do perímetro urbano. "A iluminação pública foi substituída por eletricidade, os carros puxados a boi foram substituídos por bondes elétricos. E não podemos deixar de falar na preocupação de Lemos pelas áreas verdes da cidade" (TOCANTINS, 1987 apud MATOS, 1999, p. 7).

Antônio Lemos, intendente/governador, preocupado com o embelezamento da cidade, providenciou reformas em logradouros públicos para que se tornassem mais atraentes. Aliado a isso, o município sistematizou mecanismos contra a ação predatória dos cidadãos em direção às áreas verdes e aos rios, pois a arborização da cidade era uma maneira de demonstrar uma qualidade de vida saudável, ligada à natureza, com ar puro renovado pelo processo de fotossíntese; amenização do clima tropical, além da própria beleza de uma cidade arborizada.

Abordando as modificações de cunho paisagístico, vale ressaltar que no governo de Augusto Montenegro, Belém foi ornamentada com jardins e bosques. Segundo Brasil (1995 apud Matos, 1999) o arquiteto naturalista Antônio Landi, em 1780, numa tentativa de amenizar a falta da vegetação natural, estudava a introdução na região da mangueira, pois ela oferecia ampla e perfeita sombra, 
onde a população poderia fugir do sol ardente da cidade. Nesse contexto, os grupos urbanos da cidade passaram a ter um estreito relacionamento com a natureza, frequentando, constantemente, sítios, parques e bosques, o que gerou uma revalorização do Bosque Municipal, já existente, considerado um dos marcos da modernidade belenense. É importante frisar que o ciclo da borracha ou economia da borracha, que tantas riquezas propiciou à região amazônica, de forma específica às capitais Manaus e Belém, foi o grande motivador das transformações urbanas e da consolidação da cidade de Belém como metrópole.

\subsection{O Bosque Rodrigues Alves: histórico e caracterização}

Fundado no final do século XIX, em meio à ebulição cultural e econômica favorecida pela extração da borracha, o Bosque Rodrigues Alves foi projetado para ser uma espécie de reserva ambiental da região, além de ser uma das medidas tomadas pela administração do intendente Antônio Lemos para garantir o embelezamento visual da cidade. Como já retratado, nesse período, Belém era o centro da reprodução do capital e da acumulação de riquezas pela burguesia internacional; vivia a "Belle Èpoque"; e precisava se adequar às necessidades dessa elite, adquirindo características de uma sociedade europeia, com seus hábitos e costumes. Nesse sentido, O Bosque Municipal tem sua criação interligada aos ideais progressistas do século XIX, que valorizavam a natureza como expressão de progresso e higiene. Localizado no periférico bairro do Marco da Légua, região para onde a cidade começou a se expandir, conforme as formulações urbanísticas promovidas por Antônio Lemos; o Bosque foi criado pela Lei $n^{\circ}$. 624, de 22.09.1870, assinada pelo Sr. Abel Graça, $4^{\circ}$ Vice-Presidente da Província do Grão Pará, que determinava a figura e extensão de um terreno destinado para esse fim na Estrada de Bragança.

Se para a elite local, a Europa era o espelho de toda e qualquer modernização, consequentemente, os valores estéticos e ideológicos 


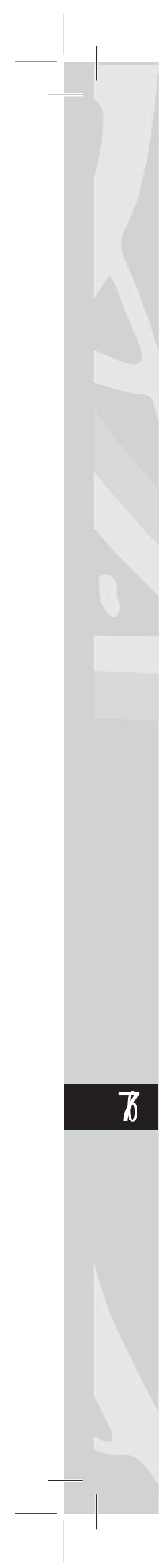

europeus, especialmente os franceses, foram importados pela sociedade amazônica. A urbanização então foi baseada nas concepções "cidade jardim" e Paris hausmaniana. O governador Augusto Montenegro e o intendente Antônio Lemos, porta-vozes deste projeto, recriaram uma Belém com ornamentos de jardins e bosques, abrindo grandes artérias verdes. Reproduz-se os amplos boulervards franceses.

Visando interligar Belém com o interior do Estado, especificamente com a zona bragantina, é construída a estrada de ferro Belém-Bragança. A ferrovia surgiu em decorrência do acentuado crescimento da exportação do látex do interior do Estado para a capital, o que exigia um sistema de transporte mais moderno para o escoamento da produção, bem como para o transporte de pessoas. Sua construção foi iniciada em 1883 e inaugurada em 1908, nascendo no atual bairro de São Braz. Assim, a malha ferroviária começou a penetrar o interior e as novas áreas abertas, a partir do Marco da Légua, foram ocupadas.

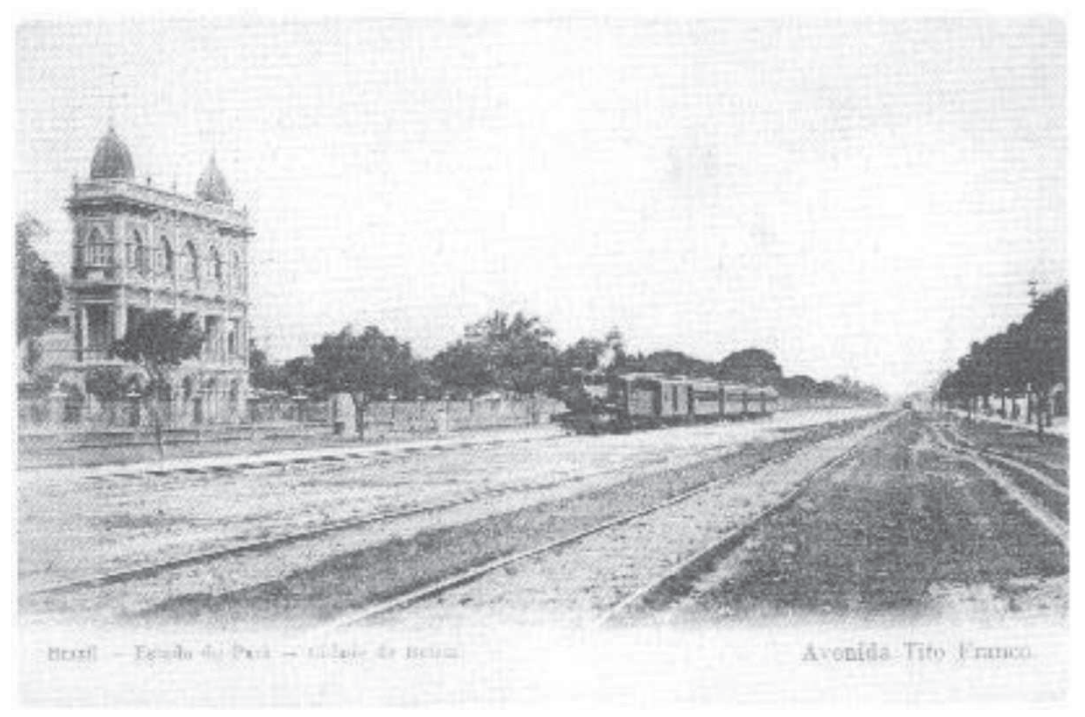

Figura 1: Trem de Carga. Estrada de Ferro de Bragança

Fonte: Álbum do Pará, 1899. 


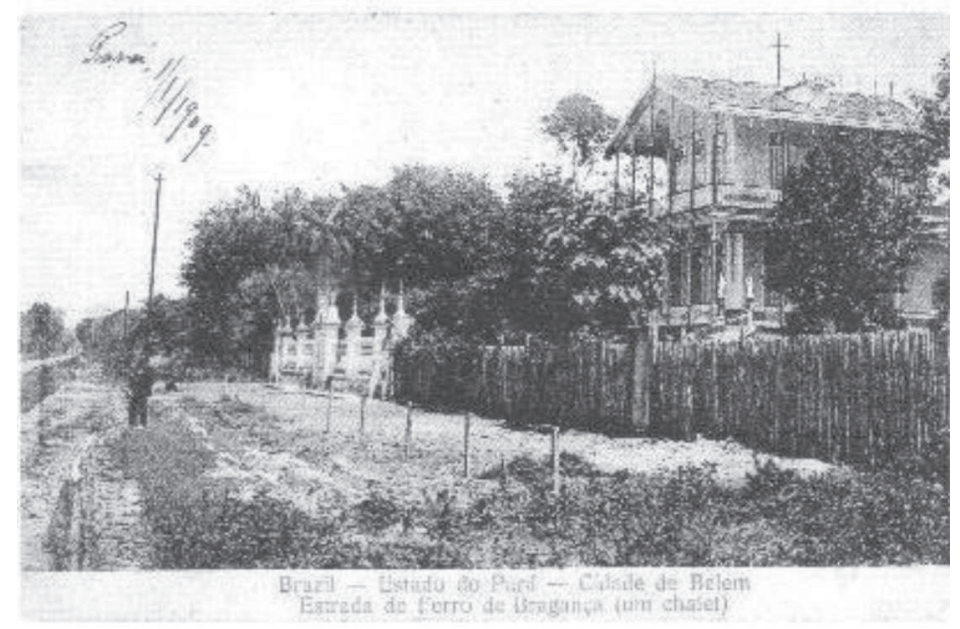

Figura 2: Estrada de Ferro de Bragança. Fonte: Álbum do Pará, 1899.

$\mathrm{Na}$ margem da estrada, nas cercanias do Bosque Municipal, belas edificações públicas e particulares foram construídas. Essa ocupação na zona periférica da cidade era o retrato do isolamento das famílias ricas, que buscavam nessas áreas o descanso do agitado centro urbano da cidade.

\subsection{Um estudo sobre representação social e seus conceitos}

A representação social, sujeita às influências de condições econômicas e culturais, estabelece a interface entre o social e o psicológico. No cotidiano, o sujeito elabora, individual e coletivamente, imagens e conceitos, que podem ser recebidos por um só indivíduo e/ou de forma coletiva. Nesse sentido, a representação social é formada e compartilhada socialmente sobre coisas, pessoas e objetos existentes em um dado espaço, uma vez que sua construção se dá na relação dos sujeitos entre si e com objetos, sendo que não há representação social sem objeto e sem sujeito social, coletivo ou individual, pertencente a um determinado grupo. (JODELET, 2001). 


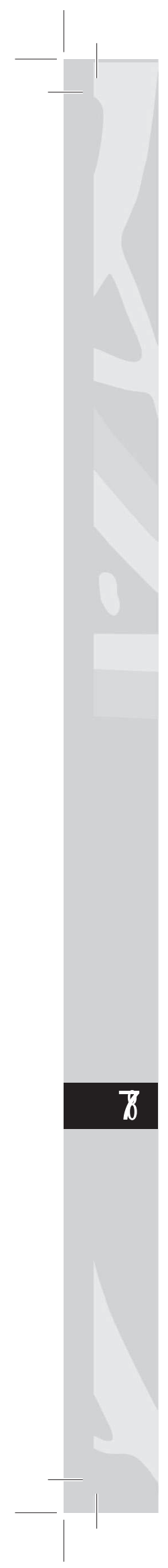

A representação social é, portanto, uma forma de conhecimento, construída e compartilhada com uma intenção prática, que coopera na formação de uma realidade comum a um dado conjunto social. Isso ocorre em decorrência da sua importância na vida social e do esclarecimento possibilitador dos processos cognitivos e das interações sociais. Tanto que a representação tem o termo "social" ligado a seu nome porque se configura como uma espécie de conhecimento popular com funcionalidade na elaboração de comportamentos e no estabelecimento de comunicação entre indivíduos.

Para Moscovici (2001), a representação é constituída de informação, atitude e campo de representação ou imagem. A informação se refere à organização dos conhecimentos que um dado grupo absorve sobre um objeto; atitude diz respeito à organização global sobre o objeto e age sobre este na perspectiva de uma possível teorização; enquanto que o campo envolve a ideia de imagem, de modelo social, do conteúdo das proposições acerca de um aspecto específico do objeto. Vale ressaltar que estas três dimensões estão em permanente processo de articulação.

De acordo com Jodelet (2001), as representações sociais são fenômenos complexos sempre ativados e em ação na vida social. Em sua riqueza como fenômeno, descobrimos diversos elementos (alguns, às vezes, estudados de modo isolado): informativos, cognitivos, ideológicos, normativos, crenças, valores, atitudes, opiniões, imagens etc. Contudo, esses elementos são organizados sempre sob a aparência de um saber que diz algo sobre o estado da realidade.

Segundo a autora, geralmente, considera-se que as representações sociais norteiam e organizam as condutas e as comunicações sociais, pelo fato de se consubstanciarem como sistemas de interpretação que regem as relações do indivíduo com o seu espaço circundante e com aqueles que o rodeiam. $\mathrm{Na}$ mesma intensidade, elas são responsáveis por intervenções nos mais variados processos, como: a propagação e a absorção dos conhecimentos; o crescimento individual e coletivo; a definição das identidades pessoais e sociais; a expressão dos grupos e as transformações sociais. 
Além do mais, ao se configurarem como fenômenos cognitivos, abarcam a pertença social dos indivíduos com as implicações afetivas e normativas, com as interiorizações de experiências, práticas, modelos de condutas e pensamentos, socialmente inculcados ou transmitidos pela comunicação social, que a ela estão ligadas. Desse ponto de vista, as representações sociais são abordadas concomitantemente como produto e processo de uma atividade de apropriação da realidade exterior ao pensamento e de elaboração psicológica e social dessa realidade.

\section{Metodologia}

Neste tópico, é abordado o percurso metodológico, no sentido de responder ao problema central que nos convocou a esta trajetória, qual seja: quais são as representações sociais dos moradores da cidade de Belém com relação ao Bosque Rodrigues Alves? A teoria da representação social não especifica um método próprio de investigação. Sua elaboração depende do objeto de estudo e do pesquisador, sem desconsiderar que o método eleito terá o desafio de apreender a construção complexa e dinâmica das representações sociais. Utilizando-nos de uma linguagem figurada, é como se no meio da mata tivéssemos que encontrar um caminho de saída, e para isto elegemos uma trilha que pensamos ser coerente com nossos objetivos (FARR, 1993 apud SÁ, 1998).

Vale ressaltar que o estudo foi conduzido por meio de uma abordagem qualitativa e quantitativa que, por um lado, permite compreender, a partir do estudo qualitativo, "as representações de determinado grupo sobre temas específicos” (MINAYO; MINAYO, 1994), e, por outro, "explicar os dados", apoiados na tabulação destes. Isso permite maior aproximação do objeto deste estudo, como também maior rigor às inferências sobre o caleidoscópio que configura o objeto de estudo em tela.

O objeto de pesquisa desse trabalho são as representações sociais do Bosque Rodrigues Alves, situado em Belém do Pará, uma 


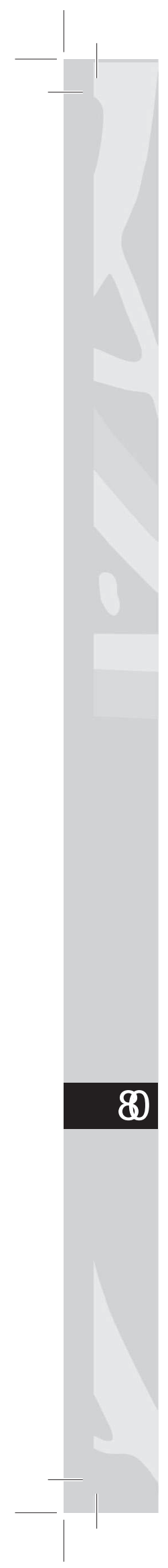

das principais capitais da região Norte. O espaço verde se entrelaça ao espaço construído. Os bancos de concretos, situados logo após a entrada do Bosque, e outros mais no seu interior, são convidativos para a contemplação de árvores centenárias, que nem por isso perderam seu viço e deixaram de seduzir quem adentra esta "mata urbana". A existência de um lago dá ao bosque uma sinergia, com o verde, a fauna e a arquitetura, que remonta aos áureos tempos da cidade.

O critério de escolha deste objeto de estudo, o Bosque Rodrigues Alves, deu-se por ser este uma das áreas verdes situada em determinada região da cidade de Belém que corresponde a uma das entradas e saídas principais dessa cidade.

O número de sujeitos obedeceu à seguinte lógica: em função do número de frequentadores, entre os meses de janeiro e fevereiro (26.000 pagantes), determinamos a amostra a ser investigada com uma margem de $95 \%$ de erro. Mediante o resultado do cálculo, a amostra determinada foi de 394 sujeitos.

Foi utilizado, como instrumento de pesquisa o questionário, traduzido como importante ferramenta neste estudo, além do levantamento bibliográfico pertinente para elaboração deste trabalho. A construção do(s) questionário(s) visa possibilitar não apenas a descrição das representações sociais, mas também situar cada objeto de representação e cada tema abordado em relação às correntes teóricas definidas, permitindo indicar o interesse de cada questão para definir o objeto da representação social. Além da caracterização dos sujeitos, foram construídas questões abertas e fechadas.

Para alcançar estes objetivos, o questionário foi construído com base em categorias elaboradas que facilitasse a identificação da representação do Bosque para os seus frequentadores. As categorias elaboradas foram: caracterização dos sujeitos, entendimento do Bosque, Percepção do tempo passado, presente e futuro do Bosque e Atitudes em relação à conservação do Bosque.

A validação do instrumento de coleta de dados foi assegurada pela aplicação de um pré-teste dos questionários a amigos e familiares, a fim de se aperfeiçoar o instrumento de pesquisa, o aumento à 
margem de confiabilidade dos dados coletados. Os dados coletados foram tabulados no software Excel, com simultânea construção de tabelas para auxílio na compreensão de sua interpretação. Após a tabulação dos questionários, foi possível estabelecer as respostas mais frequentes dentro das categorias temáticas. Para realizar a análise dos dados coletados, tomou-se como base: A análise interpretativa do questionário, entendida como um conjunto de técnicas de análise das comunicações (BARDIN, 1977, p. 31). Seu objetivo é a inferência de novos conhecimentos que fundamentam a compreensão sobre os significados consensuais dos sujeitos da amostra sobre o Bosque Rodrigues Alves. A dimensão cognitiva, a dimensão temporal e afetiva e a dimensão tendência positiva ou negativa à conservação do Bosque funcionarão como temáticas macro, que agruparão as respostas dos sujeitos da amostra. Estas dimensões revelarão as imagens e sentidos consensuais que os sujeitos deste estudo possuem sobre o Bosque.

\section{As representações sociais do Bosque Rodrigues Alves - Jardim Botânico da Amazônia - pelos seus frequentadores}

O Bosque constitui um espaço muito utilizado para reunião e realização de cultos religiosos. Em vários dias, durante a coleta de dados, muitos cultos foram realizados e alguns sujeitos foram encontrados regularmente tentando levar visitantes para suas igrejas. Com relação ao estado civil dos frequentadores, constatou-se que $75 \%$ são solteiros; $2 \%$ são viúvos; $6 \%$ possuem um outro estado civil, não contemplado nas alternativas; $2 \%$ são desquitados, divorciados, separados judicialmente e $15 \%$ são casados. A maior parte dos sujeitos que compuseram a pesquisa é oriunda da cidade de Belém, sobressaindo-se o Distrito Administrativo do Entroncamento, o qual abrange os seguintes bairros: Águas Lindas, Aurá, Castanheira, Curió-Utinga, Guanabara, Mangueirão, Marambaia, Souza, Valde-Cães, Barreiro, Maracangalha, Miramar, Pedreira, Sacramenta e Telégrafo. 


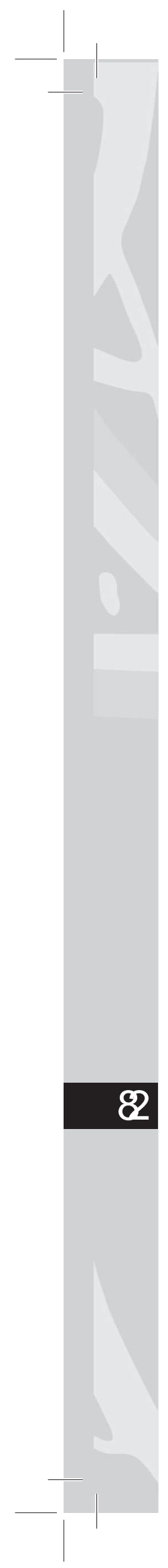

Traçando uma análise comparativa com a época do surgimento do Bosque, por meio do trabalho de Sarges (2002), pode-se perceber que o perfil dos frequentadores mudou sensivelmente. No período do surgimento do Bosque, esse perfil consistia na classe elitista da cidade, atrelada à economia da borracha naquele momento. Esses frequentadores eram compostos pelas famílias mais abastadas da cidade, elite de fazendeiros, comerciantes, profissionais liberais e grandes seringalistas, oriundos do antigo centro do comercial da cidade. A região onde hoje se localiza o Bosque, no início do século passado ainda era considerada periferia.

Também foi indagado aos sujeitos da pesquisa quais informações históricas estes possuíam sobre o Bosque, em que 41\% responderam que têm conhecimento de que o Bosque surgiu em decorrência do ciclo da borracha na Amazônia, no fim do século XIX; 35\% assinalaram não ter nenhuma informação sobre o histórico do Bosque; 8\% sabem que em 1906 o Bosque Municipal do Marco da Légua, passou a denominar-se Bosque Rodrigues Alves, em homenagem ao Presidente da República; 6\% sabem que o atual Bosque Rodrigues Alves - Jardim Botânico da Amazônia, foi criado inicialmente com o nome de Bosque Municipal do Marco da Légua; $5 \%$ têm conhecimento que o Chalé de ferro pertencia à sociedade Beneficente Portuguesa; 4\% sabem que o Bosque foi inspirado pelo "Bois Bolonge", um tradicional logradouro parisiense; apenas $1 \%$ dos entrevistados disse ter outras informações sobre o histórico do Bosque.

Muitos entrevistados comentaram, no ato desta questão, sobre o pouco conhecimento a respeito da história da Amazônia, problematizando a educação básica regional. Foi deixado claro que, apesar de a história da Amazônia fazer parte do conteúdo programático aplicado no ensino fundamental e médio, a atenção direcionada a esta temática, na região, ainda é tratada com bastante displicência pela Secretária de Educação do Estado e Município, no aspecto macro e nas escolas no âmbito micro. Contudo, outra problemática que emergiu com a pesquisa foi a observação de que o próprio Bosque 
negligencia aos seus visitantes informações sobre sua história. No Bosque, não é possível encontrar nenhum guia para acompanhar os frequentadores, apresentar o espaço, falar de sua flora, fauna e de sua história. A maior parte das atividades que a instituição desenvolve é para o público infantil, enquanto a maior parte dos seus visitantes, que é formada por adolescentes e adultos, não dispõe de atividades para sua faixa etária.

Com relação à importância do Bosque para a cidade de Belém, a alternativa de maior ocorrência assinalou que o Bosque é um espaço de lazer, $26 \%$; $24 \%$ pensam que o Bosque é importante por ser um espaço de preservação do verde; $13 \%$ consideram-no um espaço de descanso/passatempo/reflexão; $12 \%$ consideram o bosque importante por ser um patrimônio histórico; $5 \%$ concordam que o Bosque é importante por ser um espaço cultural; $5 \%$ acreditam ser ele importante por ser um espaço turístico; $5 \%$ acreditam ser um importante espaço de preservação animal; 3\% acham-no importante por ser um espaço educativo; $1 \%$ pensa que é uma floresta sem utilidade; $1 \%$ acha um importante local de pesquisa; $1 \%$ considera importante por ser um espaço religioso; $1 \%$ opinou ser importante no auxílio ao controle de poluição do ar; $1 \%$ pensa ser um importante espaço de diversão; $1 \%$ acredita ser importante na diminuição do calor; $1 \%$ afirma que o espaço é importante para decoração da cidade; $0 \%$ acha importante por auxiliar no controle do vento; $0 \%$ acha importante por oferecer oportunidade de trabalho e $0 \%$ atribuiu outro elemento que torna o Bosque importante para a cidade de Belém.

Pode-se perceber, com os dados desta questão, que grande parte dos sujeitos da pesquisa considera o Bosque um importante espaço de lazer, além de representar um espaço de preservação do verde. Com relação a este último dado, mesmo constatando que os sujeitos acreditem que o Bosque é importante na preservação da flora, foram observadas várias formas de maus-tratos que esta sofre por boa parte dos frequentadores, como lixo atirado entre as plantas, pessoas caminhando sobre os canteiros, pisoteando a vegetação mais baixa.

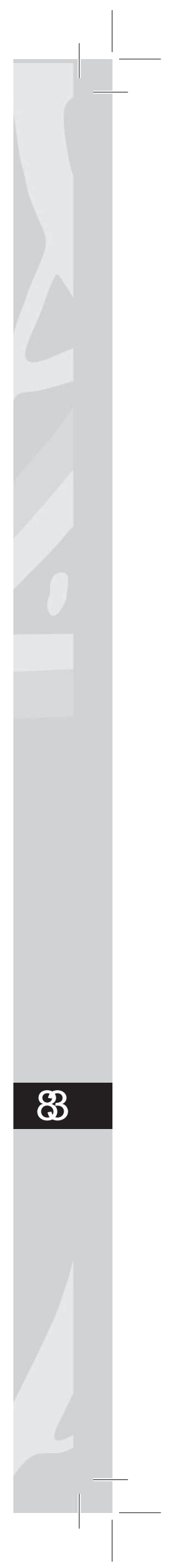




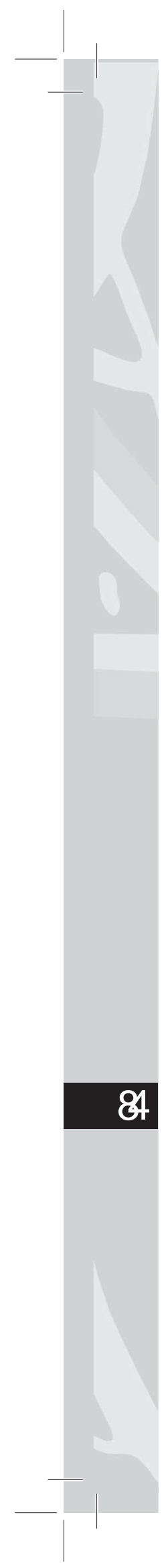

Durante a coleta de dados, foi possível examinar diferentes formas de visualização e percepção da natureza, por meio da heterogeneidade de comportamentos observados. Também foi possível constatar, no decorrer do desenvolvimento da pesquisa, que metade dos entrevistados não possui nenhum conhecimento sobre o histórico do Bosque, assim como a maior ocorrência de sujeitos atribui como importância do Bosque para a cidade de Belém o fato de ele ser um local de lazer. No momento do surgimento do Bosque, a criação de áreas verdes como esta buscava uma vida saudável, com objetivo de melhorar a qualidade de vida das pessoas e intensificar a relação entre o homem e a natureza. A criação do Bosque e de outros parques, naquele momento, funcionava como instrumento que dificultasse a ação predatória do homem sobre a natureza. Segundo Matos (1999), havia uma preocupação, por parte dos dirigentes locais, de melhorarem o conforto ambiental urbano. Neste momento, já era possível perceber que a natureza não poderia ser compreendida como matéria mensurável, passível apenas de análise quantitativa, mas passava a adquirir um valor subjetivo, uma vez que materializavam também representações culturais e históricas.

\section{Considerações finais}

O presente estudo buscou incorporar a problemática ambiental aos estudos urbanos, a partir de uma vertente teórica, representação social à luz da psicologia social. As representações, ou modos de pensar, atravessam a sociedade exteriormente aos indivíduos isolados e formam um complexo de ideias e motivações que se apresenta a eles já consolidado. Neste cenário, vale ressaltar que as representações individuais não podem ser ampliadas para a coletividade, mas sim o contrário.

No caso do estudo em foco, a partir da hipótese central das representações sociais que os frequentadores do Bosque Rodrigues Alves possuem sobre este espaço, buscou-se caracterizar as imagens e os sentidos deles sobre essa área verde. O instrumento de pesquisa 
aplicado teve por objetivo registrar as representações dos visitantes sobre o Bosque e posteriormente compará-las entre si, procurando identificar os sentidos comuns e, em contrapartida, enfatizar a diversidade de representações encontradas entre os sujeitos da pesquisa.

Assim, de acordo com a pesquisa elaborada, tornou-se possível abstrair conclusões relevantes sobre o perfil dos frequentadores do Bosque e que sentido eles atribuem a este espaço. Primeiramente, com relação ao perfil dos visitantes, percebeu-se que a maior parte deles são homens, na faixa etária entre 15 e 18 anos, estudantes, que se consideram de cor parda/morena, de religião católica, com escolaridade de nível médio, de baixa renda, a maioria pertencente à cidade de Belém, com maior ocorrência de visitantes oriundos do Distrito Administrativo do Entroncamento.

Desde o seu "nascimento", o Bosque Rodrigues Alves sofreu inúmeras alterações no seu espaço físico. A cobertura vegetal foi plantada, exibindo espécies que inexistiam na vegetação original. Estas transformações fazem com que fantasias e memórias engrenem num movimento contínuo de destruição e reconstrução, preservando inclusive a memória do passado da cidade.

Foi constatado também que uma grande representatividade, metade dos sujeitos, não possui sequer nenhum conhecimento do histórico do Bosque. Num primeiro momento, esses dados levam a criticar severamente a estrutura de ensino oferecida pelas escolas. Todavia, deve-se ressaltar que, antes de qualquer outro órgão, o próprio Bosque é responsável pela apresentação do espaço. As atividades que são desenvolvidas possuem como público-alvo as crianças, quando na verdade quem mais frequenta o Bosque são adolescentes e adultos. Quando há panfletos, estes são distribuídos de forma econômica, e o Bosque não dispõe de nenhum guia para mostrar o espaço. Às vezes os próprios guardas desempenham esta função.

A ineficiência na estratégia de divulgar as atividades desenvolvidas no Jardim Botânico e de estabelecer vínculos mais sólidos com os frequentadores faz com que o visitante acabe por 


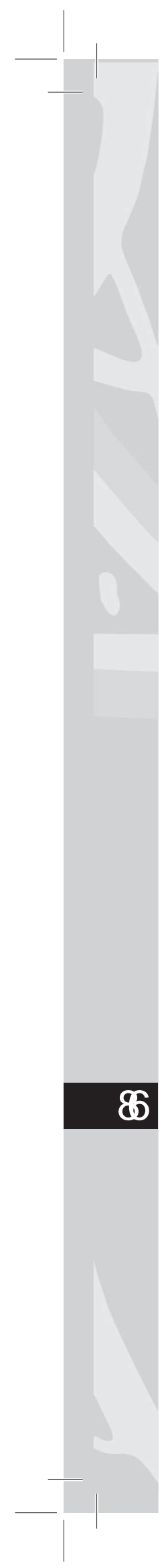

estabelecer relações de cunho emocional com este espaço, e não racional, no que diz respeito à conscientização ambiental. Também, a falta de compromisso com a questão ambiental, pôde ser observada por meio de atos de alguns visitantes, como jogar lixo em local impróprio e caminhar em lugares inapropriados. O lazer por lazer, a distração, a reflexão e a construção de laços afetivos (pais e filhos, namorados etc. fazem com que a preocupação com a preservação da natureza não seja uma das prioridades dos visitantes. Esta realidade faz com que seja bem interessante a realização de um estudo da representação social do Bosque para os seus frequentadores, para se entender que tipo de relações sociais ocorre nesse espaço, que se constitui como "espaço de convívio", uma vez que diferentes "grupos sociais" frequentam o lugar com as mais diversas intenções. As reformas feitas com longas lacunas de tempo leva a deduzir que as políticas ambientais de preservação são utilizadas apenas como instrumento na tática eleitoral.

Atualmente, a urbanização é um modo de vida, com diferentes territorialidades que revelam mobilidades, deslocamentos, reflexos da produção, do consumo, dos movimentos sociais, das ideias etc. A natureza, na análise ambiental, e o urbano são considerados de forma fragmentada ou segmentada, quase sempre não articulados com a produção e o consumo. Nesse processo de interferência do homem no espaço, a criação de parques e demais áreas verdes protegidas ganham destaque dentro do processo de urbanização.

Assim, no caso específico do Bosque Rodrigues Alves, considera-se de grande importância a realização de um estudo sobre a representação social desse espaço para os seus frequentadores, em que se destacaria o reconhecimento e a importância da cultura e da memória impregnada em cada fragmento físico desse lugar, que, direta ou indiretamente, contribuiu para a significação daquele espaço para as pessoas que moram na cidade, refletindo inclusive na sua vida social, como frequentar ou não o Bosque, ter boas ou más lembranças do espaço etc. Os efeitos da intervenção humana, em especial a construção de áreas verdes em cidades, além da intervenção física que se provoca no ambiente, possuem significativos reflexos no padrão de 
comportamento das pessoas, assim como interferem diretamente na formação cultural e histórica de um grupo social.

A proposta desse trabalho foi fazer uma investigação sobre a representação da natureza e da paisagem, mostrando seu percurso no decorrer da história, buscando caracterizar as significações da natureza, muito utilizada na contemporaneidade como "espaço de convívio", sempre na perspectiva da relação homem-natureza, considerando-se as necessidades ambientais e o tipo de relação que o homem vem construindo no tempo e no espaço com o meio ambiente e o posicionamento das políticas públicas neste processo.

Sendo assim, ressalta-se a necessidade de que seja iniciada, no âmbito das políticas públicas, uma reflexão centrada no descaso com o qual as áreas verdes de Belém vêm sendo tratadas e o reflexo negativo que este descaso traz ao comportamento e à qualidade de vida da população urbana da cidade.

A temática ambiental tem caráter político. Por isso, no âmbito das políticas públicas, a temática ambiental deve ser tratada com mais seriedade, uma vez que estas reflexões transmitem modelos de vida, de trabalho, de relacionamento, de condutas. Neste sentido, a comunicação deve atuar como ferramenta para despertar o interesse por parte do poder público e de entidades privadas, para promover novos tratos com a questão ambiental. No domínio das políticas públicas, a abordagem integrada dos problemas urbanos, enfocados sob a ótica do meio ambiente, vem aos poucos ganhando espaço, podendo gerar uma nova agenda de questões a ser contemplada no planejamento e na gestão das cidades, que hoje, quando ocorre, é de maneira ineficiente.

O Poder Público tem que ocupar as áreas desprotegidas e viabilizar os parques e as praças já existentes, dotando-os de infraestrutura, de segurança e de serviços que aproximem a comunidade dessas áreas, no sentido de protegê-las e preservá-las para melhorar a qualidade de vida das cidades. O desenvolvimento de pesquisas na área social pode ajudar a compreender as dimensões humanas de manejo de áreas verdes em cidades, contribuindo para 
o desenvolvimento de um turismo com sensibilidade ecológica e incorporar as necessidades e as preocupações das comunidades locais, assim como gerar informação como estes grupos afetam os recursos naturais. A informação derivada da pesquisa pode ser usada para educar a população acerca de seu impacto sobre os recursos naturais e também acerca do impacto que uma área de conservação pode ter sobre o seu modo de vida.

A ocupação urbana, adequada à preservação das áreas verdes em cidades, somente poderá ser conduzida de modo eficaz se os agentes sociais perceberem os recursos naturais renováveis, dentro de um quadro de escassez, como elementos indissociáveis de padrões de qualidade mínimas e sensíveis ao dinamismo das atividades sociais, bem como compreenderem as relações entre o ser humano e a natureza.

\section{REFERÊNCIAS}

BARDIN, Laurence. Análise de conteúdo. Lisboa: Edições 70, 1977.

DAMATTA, Roberto. Conta de mentirosos: sete ensaios de antropologia brasileira. Rio de Janeiro: Rocco, 1993.

JODELET, Denise (Org.). As representações sociais. Rio de Janeiro: Ed. UERJ, 2001.

MINAYO, M. C. S.; MINAYO, M. O conceito das representações sociais na sociologia clássica. In: CORENDA, Pedrinho (Org.). Textos sobre representações sociais. Petrópolis: Vozes, 1994.

MOSCOVICI, Serge. Das representações coletivas às representações sociais: Elementos para um a história. In: JODELET, Denise (Org.). As representações Sociais. Rio de Janeiro: Ed. UERJ, 2001. 